\title{
Study on Biocompatibility and Mineralization Potential of Capseal
}

\author{
Kwang Shik Bae ${ }^{1}$, Seok Woo Chang ${ }^{2}$, Kee Yeon Kum ${ }^{1}$, Woo Cheol Lee ${ }^{1}$ \\ 'Department of Conservative Dentistry, Dental Research Institute, Seoul National University Dental Hospital, \\ School of Dentistry, Seoul National University, ${ }^{2}$ Department of Conservative Dentistry, School of Dentistry, \\ Kyung Hee University, Seoul, Korea
}

Purpose: Capseal I and Capseal II are calcium silicate and calcium phosphate based experimental root canal sealers. This study sought to evaluate the biocompatibility and mineralization potential of Capseal I and Capseal II.

Materials and Methods: The biocompatibility and mineralization related gene expression (alkaline phosphatase [ALP], bone sialoprotein [BSP], and osteocalcin) of Capseal I and Capseal II were compared using methylthiazol tetrazolium assay and reverse transcription-polymerization chain reaction analysis, respectively. The results were analyzed by Kruskal-Wallis test. A P-value of $<0.05$ was considered significant.

Result: Both Capseal I and Capseal II were favorable in terms of biocompatibility, influencing the messenger RNA expression of ALP and BSP.

Conclusion: Within the limitation of this study, Capseal is biocompatible, with mineralization promoting potential; thus, it could be a promising root canal sealer.

Key Words: Biocompatibility; Capseal I; Capseal II; Mineralization related gene expression

\section{Introduction}

Mineral trioxide aggregate has been introduced in the early 1990s in the endodontic field as root end filling material ${ }^{1,2)}$ and perforation repair material ${ }^{3)}$. Since then, it has long been successfully used in clinical endodontics, with its use expanded to fields such as one-visit apexification ${ }^{4)}$, pulp capping ${ }^{5)}$, and pulpotomy. Mineral trioxide aggregate is known to be based on calcium silicate cement, and its main constituents are tricalcium silicate and dicalcium silicate ${ }^{6}$. Recently, many calcium silicatebased endodontic cements have been developed by various companies ${ }^{7-9)}$. Capseal is one of the ex-

Corresponding Author: Woo Cheol Lee

Department of Conservative Dentistry, Dental Research Institute, School of Dentistry, Seoul National University, 101 Daehakro, Jongno-gu, Seoul 110-749, Korea

TEL : +82-2-2072-2651, FAX : +82-2-2072-3859, E-mail : hockeyducky@gmail.com

Received for publication April 6, 2014; Returned after revision May 21, 2014; Accepted for publication May 28, 2014

Copyright $\odot 2014$ by Korean Academy of Dental Science

(cc) This is an open access article distributed under the terms of the Creative Commons Attribution Non-Commercial License (http://creativecommons.org/licenses/ by-nc/3.0) which permits unrestricted non-commercial use, distribution, and reproduction in any medium, provided the original work is properly cited. 
perimental root canal sealers that are based on calcium silicate and calcium phosphate. An ideal root canal sealer should provide hermetic sealing of the root canal; it should be bacteriostatic, and it should neither shrink upon setting nor irritate the periradicular tissue ${ }^{10)}$. Capseal was reported to have good root canal sealing ability ${ }^{11)}$ and biocompatibility ${ }^{12-14)}$ in previous studies.

Based on previous research demonstrating that calcium silicate based endodontic cement is biocompatible, and that it has potential to promote the formation of mineralized tissues ${ }^{15,16)}$, it is worth investigating the biocompatibility and its ability to promote mineralized tissue formation. This study sought to investigate the biocompatibility and osteogenic potential of the experimental root canal sealer, Capseal.

\section{Materials and Methods}

In this study, experimental root canal sealers Capseal I and Capseal II were used. The constituents of Capseal I and Capseal II are listed in Table 1. The main components of Capseal are calcium silicate and calcium phosphate. The liquid contains hydroxyprophyl methylcellulose.

\section{Cell Culture and Cytotoxicity Test Using Me- thylthiazol Tetrozolium Assay}

In this experiment, MG-63 human osteosarcoma cells were used. The cells were cultured in Dulbecco's modified Eagle's medium supplemented with 10\% (vol/vol) fetal bovine serum (Gibco, Grand Island, NY, USA) and 1\% (wt/vol) anti- biotics/antimycotics (100 U of penicillin, $100 \mu \mathrm{g}$ of streptomycin, and $0.25 \mu \mathrm{g}$ of amphotericin B; Gibco) at $37^{\circ} \mathrm{C}$ in a humidified $5 \%$ (vol/vol) $\mathrm{CO}_{2}$ atmosphere. One gram of Capseal I and II was mixed with liquid in a $1: 1$ water to powder ratio. After mixing, the materials were inserted into sterilized molding rings with inner diameter of $5 \mathrm{~mm}$ and thickness of $1 \mathrm{~mm}$. Thereafter, the materials were set at room temperature for 3 hours with humidity of $97 \%$. One millimeter of medium containing $5 \times 10^{4}$ of MG-63 cells was then seeded into each well in the 24-well plates. TheMG-63 cells were cultured with a culture plate insert with set Capseal I and II specimen on top of the culture plate insert. Empty tubes were used as the control group. After 6 and 18 hours of incubation, cell viability was evaluated using a methylthiazol tetrazolium (MTT; 3-[4,5-dimethylthiazol-2yl]-2,5-diphenyl2H-tetrazolium bromide) assay kit. The cells were incubated with $5.7 \mathrm{~mol} / \mathrm{L}$ of MTT solution in a tissue culture incubator for 4 hours. Thereafter, $200 \mu$ of dimethyl sulfoxide solution was added to the cell culture wells. The plates were then shaken for 10 minutes at room temperature to dissolve the precipitated formazan crystals. The solutions were centrifuged for 10 minutes, and the optical density of the supernatant was measured using an enzyme-linked immunosorbent assay plate reader (PowerWave; BioTek Instruments, Winooski, VT, USA) at $540 \mathrm{~nm}$. Experiments were carried out in duplicate.

Table 1. Materials used in this study

\begin{tabular}{ccc}
\hline \multirow{2}{*}{ Name } & \multicolumn{2}{c}{ Composition } \\
\cline { 2 - 3 } Capseal I & Tetracalcium phosphate and dicalcium phosphate dehydrate, & Hydroxypropyl methyl cellulose in sodium \\
& Portland cement, zirconium oxide, others & phosphate solution \\
Capseal II & Tetracalcium phosphate and dicalcium phosphate dehydrate, & Hydroxypropyl methyl cellulose in sodium \\
& white Portland cement, zirconium oxide, others & phosphate solution \\
\hline
\end{tabular}


2. RNA Isolation and Reverse Transcription-Polymerase Chain Reaction

After 3 and 7 days of culture, the total RNA of the incubated cells was extracted using Trizol reagent (Life Technologies, Gaithersburg, MD, USA) according to the manufacturer's instructions. Reverse transcription (RT) of RNA was performed using an AccuPower RT Premix (Bioneer, Daejeon, Korea), which was also utilized for amplifying the RT-generated DNA. The polymerase chain reaction (PCR) products were resolved on a 1.5\% agarose gel and stained with ethidium bromide.

\section{Statistical Analysis}

Statistical analyses of the MTT assay and RT-PCR data were performed using the Kruskal-Wallis test (SPSS Statistics version 17.0; SPSS Inc., Chicago, IL, USA). The confidence interval was $95 \%$ and a $\mathrm{P}$-value less than 0.05 was considered significant.

\section{Result}

\section{Cytotoxicity Test Using Methylthiazol Tetra- zolium Assay}

Capseal I and II showed favorable cell viability values at 6 and 18 hours' incubation times. Compared to the control, the percentage of viable cells was $110 \%$ for Capseal I and 100\% for Capseal II after 6 hours of incubation. After 18 hours of

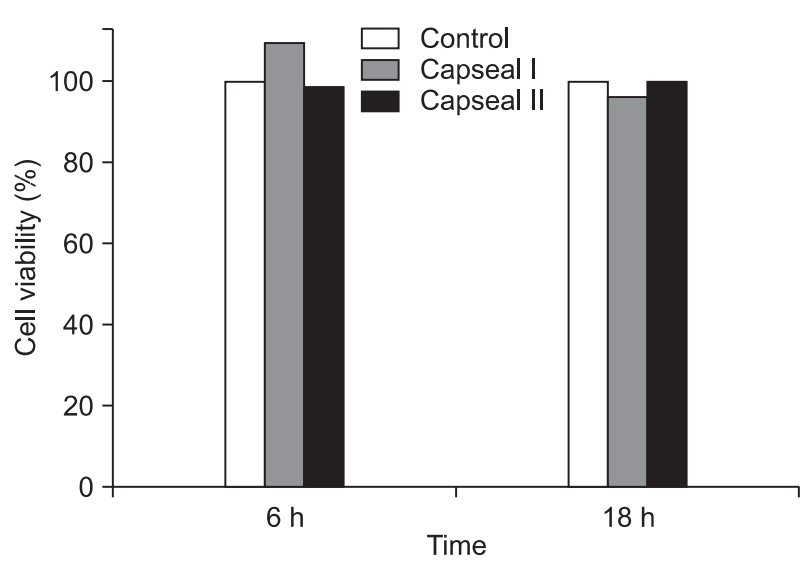

Fig. 1. The results of cytotoxicity test. incubation, the percentage of viable cells was $96 \%$ for Capseal I and 100\% for Capseal II (Fig. 1).

\section{RNA Isolation and Reverse Transcription-Po- lymerase Chain Reaction}

Although there were no statistically significant differences, the messenger RNA (mRNA) expression of ALP showed increase in the Capseal II group after 7 days of incubation compared to the control group. Likewise, BSP gene expression increased within 7 days of incubation in the Capseal I group. Osteocalcin (OCN) gene expression significantly increased within 7 days of incubation in Capseal II compared to the control group $(\mathrm{P}<0.05$; Fig. 2).

\section{Discussion}

Capseal contains both calcium silicate and calcium phosphate as its component. Based on previous research, calcium silicate produces calcium hydroxide when mixed with water; when calcium hydroxide comes in contact with phosphate ion, it could form hydroxyapatite ${ }^{6}$, which is a major constituent of human dental tissues. Since Capseal contains calcium silicate and calcium phosphate, the formation of hydroxyapatite is expected to be enhanced by the calcium phosphate in Capseal. This would be beneficial in increasing Capseal's

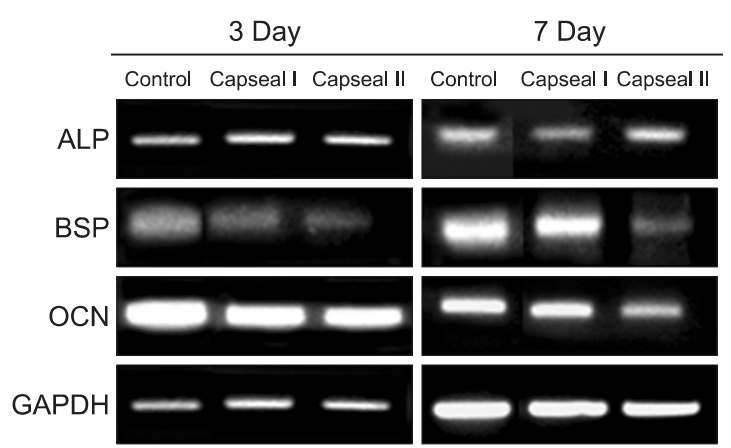

Fig. 2. The results of mineralization related gene expression test. ALP: alkaline phosphatase, BSP: bone sialoprotein, OCN: osteocalcin, GAPDH: glyceraldehyde-3-phosphate dehydrogenase. 
root canal sealing ability, which was reported to be greater than that of Sealapex. Furthermore, a recent study reported that calcium ions released from calcium silicate cement play an important role in the osteoblastic differentiation of pluripotent cells ${ }^{17)}$. Alkaline phosphatase (ALP) is one of the early markers of osteoblastic differentiation, playing an important role in mineralized tissue formati$\mathrm{on}^{18)}$. OCN is a more specific, relatively late-stage marker of osteoblastic differentiation ${ }^{19}$. Bone sialoprotein (BSP) is a major extracellular matrix component of bone produced mainly by osteoblast and is considered to be a marker of osteoblastic phenotypes ${ }^{20)}$. For this reason, the upregulation of ALP, OCN, and BSP could suggest the osteogenic potential of certain dental materials. The upregulation of ALP by mineral trioxide aggregate was reported in many previous studies using rat dental papilla ${ }^{21)}$, rat dental pulp ${ }^{22)}$, and MDPC23 cells $^{23)}$. BSP upregulation by mineral trioxide aggregate was also cited in previous studies using cementoblast $^{24)}$ and dental pulp cells ${ }^{25)}$. Since Capseal is based on calcium silicate as mineral trioxide aggregate, the results are in agreement with this study.

This study has limitations such as small sample sizes and absence of control groups using commercial root canal sealers. Thus, this study should be regarded as a preliminary pilot study. Nonetheless, this study showed the possibility of Capseal as biocompatible and bioactive root canal sealer. Further studies including in vivo and clinical trials could provide evidence for use of Capseal as root canal sealer.

\section{Conclusion}

Within the scope of this study, Capseal is biocompatible, with potential for promoting mineralized tissue formation.

\section{Conflict of Interest}

No potential conflict of interest relevant to this article was reported.

\section{Acknowledgement}

This study was supported by grant no. 04-20110051 from the SNUDH research fund.

\section{References}

1. Bodrumlu E. Biocompatibility of retrograde root filling materials: a review. Aust Endod J. 2008; 34: 30-5.

2. Asgary S, Eghbal MJ, Parirokh M, Ghoddusi J. Effect of two storage solutions on surface topography of two root-end fillings. Aust Endod J. 2009; 35: 147-52.

3. Ford TR, Torabinejad M, McKendry DJ, Hong CU, Kariyawasam SP. Use of mineral trioxide aggregate for repair of furcal perforations. Oral Surg Oral Med Oral Pathol Oral Radiol Endod. 1995; 79: 75663.

4. Chang SW, Oh TS, Lee W, Cheung GS, Kim HC. Long-term observation of the mineral trioxide aggregate extrusion into the periapical lesion: a case series. Int J Oral Sci. 2013; 5: 54-7.

5. Reston EG, de Souza Costa CA. Scanning electron microscopy evaluation of the hard tissue barrier after pulp capping with calcium hydroxide, mineral trioxide aggregate (MTA) or ProRoot MTA. Aust Endod J. 2009; 35: 78-84.

6. Chang SW. Chemical characteristics of mineral trioxide aggregate and its hydration reaction. Restor Dent Endod. 2012; 37: 188-93.

7. Chang SW, Lee SY, Kum KY, Kim EC. Effects of ProRoot MTA, Bioaggregate, and Micromega MTA on odontoblastic differentiation in human dental pulp cells. J Endod. 2014; 40: 113-8.

8. Kum KY, Kim EC, Yoo YJ, Zhu Q, Safavi K, Bae KS, Chang SW. Trace metal contents of three 
tricalcium silicate materials: MTA Angelus, Micro Mega MTA and Bioaggregate. Int Endod J. 2014; 47: 704-10.

9. Rajasekharan S, Martens LC, Cauwels RG, Verbeeck RM. Biodentine ${ }^{\mathrm{TM}}$ material characteristics and clinical applications: a review of the literature. Eur Arch Paediatr Dent. 2014; 15:147-58.

10. Hargreaves KM, Cohen S, Berman LH. Pathways of the pulp. 10th ed. St. Louis: Mosby Elsevier; 2011.

11. Yang SE, Baek SH, Lee W, Kum KY, Bae KS. In vitro evaluation of the sealing ability of newly developed calcium phosphate-based root canal sealer. J Endod. 2007; 33: 978-81.

12. Kim JS, Baek SH, Bae KS. In vivo study on the biocompatibility of newly developed calcium phosphate-based root canal sealers. J Endod. 2004; 30: 708-11.

13. Shon WJ, Bae KS, Baek SH, Kum KY, Han AR, Lee WC. Effects of calcium phosphate endodontic sealers on the behavior of human periodontal ligament fibroblasts and MG63 osteoblast-like cells. J Biomed Mater Res B Appl Biomater. 2012; 100: 2141-7.

14. Bae WJ, Chang SW, Lee SI, Kum KY, Bae KS, Kim EC. Human periodontal ligament cell response to a newly developed calcium phosphate-based root canal sealer. J Endod. 2010; 36: 1658-63.

15. Wang Y, Li J, Song W, Yu J. Mineral trioxide aggregate upregulates odonto/osteogenic capacity of bone marrow stromal cells from craniofacial bones via JNK and ERK MAPK signalling pathways. Cell Prolif. 2014; 47: 241-8.

16. Asgary S, Nazarian H, Khojasteh A, Shokouhinejad $\mathrm{N}$. Gene expression and cytokine release during odontogenic differentiation of human dental pulp stem cells induced by 2 endodontic biomaterials. J Endod. 2014; 40: 387-92.

17. Matsumoto S, Hayashi M, Suzuki Y, Suzuki N,
Maeno M, Ogiso B. Calcium ions released from mineral trioxide aggregate convert the differentiation pathway of $\mathrm{C} 2 \mathrm{C} 12$ cells into osteoblast lineage. J Endod. 2013; 39: 68-75.

18. Cormier C. Markers of bone metabolism. Curr Opin Rheumatol. 1995; 7: 243-8.

19. Malaval L, Modrowski D, Gupta AK, Aubin JE. Cellular expression of bone-related proteins during in vitro osteogenesis in rat bone marrow stromal cell cultures. J Cell Physiol. 1994; 158: 555-72.

20. Mizuno M, Imai T, Fujisawa R, Tani H, Kuboki $\mathrm{Y}$. Bone sialoprotein (BSP) is a crucial factor for the expression of osteoblastic phenotypes of bone marrow cells cultured on type I collagen matrix. Calcif Tissue Int. 2000; 66: 388-96.

21. Li FL, Que GY. Effect of mineral trioxide aggregate on proliferation and differentiation of rat dental papilla cells. Zhonghua Kou Qiang Yi Xue Za Zhi. 2013; 48: 343-7.

22. Wang Y, Yan M, Fan Z, Ma L, Yu Y, Yu J. Mineral trioxide aggregate enhances the odonto/osteogenic capacity of stem cells from inflammatory dental pulps via NF-кB pathway. Oral Dis. 2013. doi: 10.1111/odi.12183.

23. Eid AA, Niu LN, Primus CM, Opperman LA, Pashley DH, Watanabe I, Tay FR. In vitro osteogenic/dentinogenic potential of an experimental calcium aluminosilicate cement. J Endod. 2013; 39: 1161-6.

24. Hakki SS, Bozkurt SB, Hakki EE, Belli S. Effects of mineral trioxide aggregate on cell survival, gene expression associated with mineralized tissues, and biomineralization of cementoblasts. J Endod. 2009; 35: 513-9.

25. Hwang YC, Hwang IN, Oh WM, Park JC, Lee DS, Son HH. Influence of TGF-beta1 on the expression of BSP, DSP, TGF-beta1 receptor I and Smad proteins during reparative dentinogenesis. J Mol Histol. 2008; 39: 153-60. 